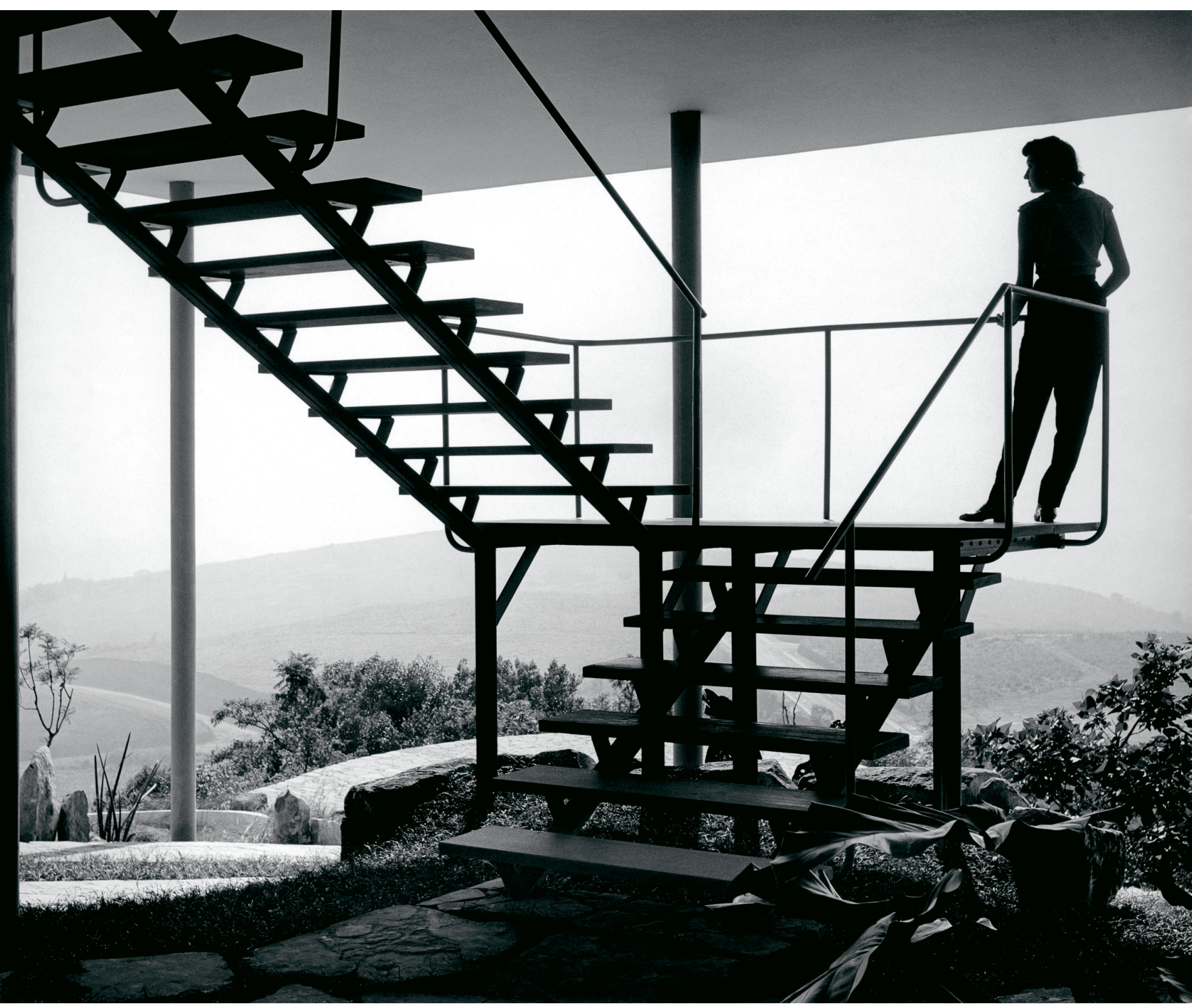




\section{Reflexos da Casa de Vidro, de Philip Johnson, arquiteto, ou o processo de trabalho de Mauro Restiffe, fotógrafo.}

\section{Reflections of Philip Johnson's Glass House, architect, or Mauro Restiffe's work process, photographer.}

palavras-chave:

Pintura, fotografia e arquitetura; vidro na arquitetura moderna; Mauro Restiffe; processo de trabalho na fotografia contemporânea; série

- Casa de Vidro

keywords:

Painting, photography and architecture; flass in modern architecture; Glass House; Mauro Restiffe; work process in contemporary photography; Glass House Series

* Universidade de São Paulo [USP].

DOI: 10.11606/issn.2178-0447. ars.2017.131497.

Lina Bo Bardi na escada de acesso à Casa de Vidro, São Paulo, 1952
"Série - Casa de Vidro" é um ensaio fotográfico realizado pelo artista Mauro Restiffe na Glass House, residência que o arquiteto norte-americano Philip Johnson (1906/2005) projetou para ele mesmo em 1949, em New Canaan, Connecticut, e onde viveu até o fim de sua vida. Além dessa residência demonstrar o profundo respeito de Johnson pela arquitetura do mestre moderno alemão Mies Van der Rohe, sua ampla divulgação contribuiu decisivamente para o êxito da arquitetura moderna nos Estados Unidos da América. Ao fotografála em uma única visita, Mauro Restiffe, articulou em 8 fotos e 9 imagens, a arquitetura da casa, o jardim que a circunda e a tela de Nicolas Poussin, desvendando, sem se dar conta, o jogo proposto pelo arquiteto entre a tela do artista francês e o jardim plantado no mesmo período de construção da casa. A análise dessa obra Restiffe tem como objetivos secundários a apresentação do jogo engendrado por Johnson e o processo de trabalho do artista.

"Series - Glass House" is a photographic experiment conducted by the artist Mauro Restiffe at the Glass House, a project designed by the North American architect Philip Johnson (1906/2005) to become his own residence in 1949, in New Canaan, Connecticut, where he lived for the rest of his life. The house not only demonstrates Johnson's profound respect for the architecture of the German modern master Mies Van der Rohe but also its wide propagation was a decisively contribution for the success of the modern architecture in the United States of America. By photographing the house in one single visit, Mauro Restiffe articulated in 8 photographs and 9 images the architecture of the house and its surrounding garden, as well as Nicolas Poussin's painting, unintentionally unveiling the dynamics suggested by the architect between the French artist's work and the garden, which was set during the building of the house. The analysis of Restiffe's work aims as secondary objectives the presentation of the dynamics fomented by Johnson and the work process of the artist. 
"Trabalhando com maquetes de vidro, descobri que o importante é o jogo de reflexos, e não os efeitos de luz e sombra como nos edifícios comuns."

Mies van der Rohe
Reflexos da Casa de Vidro, de Philip Johnson, arquiteto, ou o processo de trabalho de Mauro Restiffe, fotógrafo.

\section{Notícias sobre a arquitetura de vidro}

Construída em 1949 no vale do Rio Rippowan, em New Canaan, Connecticut, a Glass House (Casa de Vidro), do arquiteto norte-americano Philip Johnson, surpreende até hoje pelo despojamento que proporciona à noção de habitação e as de abrigo e aconchego que lhe são correlatas. Em lugar de paredes espessas e opacas e as janelas que permitem o acesso visual ao mundo de fora, fonte de curiosidade e inquietude, a casa resolve-se em dois planos horizontais retangulares do mesmo tamanho, um piso e o outro teto, ambos com bordas de aço escuro, separados por um reticulado aberto dos perfis, também de aço, dos caixilhos e pilares, e pelas placas de vidro que fazem as vezes de paredes. Uma pequena casa transparente, um cristal em meio a paisagem, ela própria paisagem, dignamente pousada diante de um gramado, na borda de um vale, tendo por trás de si um renque de árvores no qual se sobressai um carvalho, e que descai suavemente acompanhando a encosta até encontrar o espelho luminoso do lago mais embaixo.

A Glass House garantiu fama duradoura a Philip Johnson e até hoje é considerada, além de marco da arquitetura, a obra que contribuiu decisivamente para que o público norte-americano passasse a reconhecer, acostumar-se e até mesmo a desejar a arquitetura moderna. Johnson, curador de arquitetura do Museu de Arte Moderna de Nova Iorque, MoMA, depois de levar de três a quatro anos entre o projeto e a construção casa, foi o único e solitário morador desta até sua morte, em 2005, aos 98 anos. (Nem sempre, é verdade. A partir de um momento, mudou-se para o estúdio semienterrado bem ao lado, quase uma cripta protegida por uma fachada cega de tijolos, deixando a Glass House para as constantes recepções aos amigos e visitantes.) Tombada com a chancela de "National historic preservation landmark", a Glass House foi finalmente aberta ao público, profissionais e estudantes de arquitetura e interessados em 

e que as visitas deviam obedecer os "dias especificados".

Em que pese seus altos predicados a Glass House não chega a ser uma obra prima mas seconda. A razão é sua descendência direta da, esta sim, extraordinária casa que o arquiteto alemão Mies van der Rohe fez para sua amiga Edith Farnsworth, entre 1945 e 1950, e cuja maquete de vidro o próprio Johnson apresentou em uma exposição no MoMA, em 1947. Reza a lenda que o mestre alemão, ex-diretor da Bauhaus radicado desde 1933 nos Estados Unidos, reagiu muito mal à "homenagem" do seu amigo de longa data, responsável por sua primeira encomenda em solo norte-americano, nada mais nada menos que o interior do próprio apartamento de Johnson. Não obstante essas deferências, o fato da casa de Johnson ter ficado pronta antes da sua poderia sugerir que a ideia não havia sido dele, que aos olhos do público desinformado, Mies van der Rohe era o plagiário. Deixando de lado o desconforto e a grande semelhança dos dois exemplares de arquitetura, as qualidades formais e materiais - como, por exemplo, o apurado acabamento tão típico de Mies van der Rohe -, da Casa Farnsworth, superam em vários graus a obra de seu colega norte-americano, e este, aparentemente, nunca pretendeu negar a primazia do alemão. Foi um de seus grandes interlocutores, selecionou várias de suas obras para muitas exposições e, não bastasse, escreveria a importante monografia intitulada Mies van der Rohe.

Feitas as contas, todas as várias menções de Johnson reconhecendo o valor de Mies van de Rohe não diminui a importância de sua Glass House. Na qualidade de homem inspirado na combinação estratégica entre arquitetura e publicidade, Johnson, graças a ela, figura entre os que melhor defenderam e divulgaram a equação segundo a qual uma edificação aberta à luz, à natureza e à visão de quem por perto dela passa, seria mais democrática. Plantou no coração da aristocracia wasp norte-americana, no momento mesmo em que se inaugurava a política da Guerra Fria, em pleno ano da criação da OTAN,

1. MARSA, Angel; MARSILLACH, Luis. La montaña iluminada. Barcelona: Ediciones Horizonte, 1930. a ideia de que "o povo capaz de adotar essa arquitetura seria um povo de horizontes claros"1.

0 fotógrafo como produtor de imagens, assim como o vidro, uma pa- 
rede de tijolos ou quaisquer outros materiais transparentes e reflexivos ou passíveis de serem tratados como tais.

O interesse do fotógrafo Mauro Restiffe pela Glass House é um corolário de suas investigações, mais amplas do que até aqui faziam crer os escritos sobre elas. Já em sua primeira individual, em 2000, Mauro Restiffe sinalizou que pensaria a relação entre fotografia e arquitetura, incluindo pintura, paisagem e cidade, sob ângulos imprevistos. Não que suas fotos tivessem a arquitetura como tema exclusivo, afinal, sendo fotógrafo, seu problema central, ao menos até aqui, tem sido o lugar da fotografia, a plasticidade com que se aproxima e se afasta do mundo. Isso e, por extensão, a problematização da fotografia como um produto do olhar de quem a vê, não só o fotógrafo, portanto, como também do visitante que, diante de suas fotos, frequentemente percebe-se enredado num jogo no qual sua própria percepção é questionada.

Uma das peculiaridades de sua pesquisa, que o inscreveu rápida e indiscutivelmente na nossa cena artística, foi pensar a arquitetura e a cidade como fotografia e, operando por inversão, como a fotografia pode objetualizar-se e também confundir-se com a arquitetura, questão que ele enfrentou já em sua primeira exposição individual. Deve-se, contudo, advertir que, por amplo que esse escopo seja, ele não esgota o projeto poético de Restiffe, que aqui, por conveniência da análise que se fará de sua série Glass House, será reduzido às direções aludidas.

O histórico de sua relação com a arquitetura remonta, como dito, à sua primeira exposição individual, realizada em 2000 e, coincidentemente, numa casa de Gregory Warchavchik, o arquiteto ucraniano radicado em São Paulo em meados dos anos 1920, responsável pela introdução da arquitetura moderna no Brasil. Situada na avenida Europa, no bairro dos Jardins, essa casa foi adaptada no princípio dos anos 1990 como galeria de arte contemporânea do marchand Thomas Cohn.

A mostra de Restiffe chamou a atenção por ser composta de fotografias de imagens, fotografias de "segunda mão" e, especialmente, por obras não propriamente fotográficas mas pautadas em princípios fotográficos e princípios pictóricos, a um só tempo. Refiro-me ao fato de o artista, pensando a ocupação da parede lateral da primeira e maior das três salas expositivas alinhadas em sequência, ter-se dado conta de que ela dava para um corredor utilizado pela galeria como depósito. De
48

Agnaldo Farias

Reflexos da Casa de Vidro, de Philip Johnson, arquiteto, ou o processo de trabalho de Mauro Restiffe, fotógrafo. 
ARS posse dessa informação e estudando as particularidades desse correano 15 dor, resolveu abrir-lhe "três janelas", três aberturas retangulares com n. 29 dimensões semelhantes as das outras fotografias expostas.

Essas aberturas emolduraram, isto é, valeram-se de um atributo clássico da pintura para sublinhar o muro alto e branco que separava o lote da casa, onde funcionava a galeria, da casa do vizinho. Fechadas com vidro, as três aberturas, por efeito da transparência e reflexividade do material, embaralhavam as imagens de dentro e fora, ao mesmo tempo em que convertiam em imagem as visões parciais do corredor. Logo de saída, o jovem artista, de olho na expansão da fotografia, propunha a arquitetura como elemento astuciosamente associado à moldura, componente clássico da pintura - a peculiar janela que a pintura inventou para si como estratégia através da qual ela, um plano com uma imagem aplicada sobre si, historicamente afirmava sua diferença da parede, esta um plano sem maiores qualidades, seria capaz de produzir imagens. Vistas lateralmente pelo visitante em seu trânsito pela galeria, as três “janelas/molduras” refletiam o espaço expositivo e, dependendo da posição dele, também algumas das fotografias expostas.

Imagens constituídas por outras imagens, imagens produzidas por aberturas em paredes, ou por materiais reflexivos, como o vidro. Para um fotógrafo, um profissional ocupado pelo pensamento e produção de imagens, um material como o vidro, assim como outros com propriedades reflexivas, isto é, parceiros na capacidade de produção de imagens, seria naturalmente atrativo. $\mathrm{O}$ que dizer então de uma casa como a Glass House, feita de paredes de vidro, objetos e imagens? Antes de avançar nessa direção, convém mencionar que o interesse de Restiffe pela arquitetura manteve-se desde o princípio e foi ganhando corpo alimentado pelo encampamento de outras questões, dentre as quais o adensamento do seu lastro conceitual e a maturidade técnica, para o que contribuiu uma formação sólida em Cinema.

A abertura do espectro de sua pesquisa ganharia um novo patamar com o extraordinário conjunto de imagens sobre o dia da posse do presidente Lula em Brasília, em 2003. Equipado com sua indefectível câmera Leica M6, analógica, com sua lente fixa $35 \mathrm{~mm}$, sem uso de tripé ou luz artificial, fornido de um bom estoque de negativos $\mathrm{p} / \mathrm{b}$, 3200 ASA, filme de altíssima sensibilidade, "meu eterno modus operandi”, o artista rumou à Brasília para registrar o memorável dia em que a capital cartão-postal, a fotogênica cidade futurista que o estado 
brasileiro realizou em 1960 no planalto central do país, como prova de que a utopia, afinal, havia chegado, foi, finalmente, invadida, ocupada, celebrada, com muito alarido, bagunça e sujeira, pelo povo, sem a costumeira intervenção policial. Empossamento, o título dessa série fotográfica que garantiu notoriedade ao artista, mostra passo a passo, do começo ao fim, a magnífica cerimônia expressa no modo como a paisagem da Esplanada dos Ministérios, meticulosamente concebida por Oscar Niemeyer e Lucio Costa pelo ritmo constante dos paralelepípedos regulares dos prédios assentados sobre a grama impecável, o desenho irretocável das ruas que a cortam, pontuada pela presença impassível dos guardas, foi gradativamente sendo tomada por uma leva de pessoas, uma onda escorrendo pela suave colina onde nosso fotógrafo sensivelmente entendeu que deveria assestar sua câmera. Um processo desenovelado em 14 imagens. Da desatada corrida dos que primeiro queriam buscar uma posição privilegiada na cerimônia, aos espaços integralmente tomados, tendo por sobre a cabeça o cortejo dos 7 aviões-caça cortando o céu de Brasília, deixando atrás de si seu pirotécnico rastro de fumaça e júbilo, terminando no mesmíssimo ângulo da primeira foto, com os gramados novamente despovoados mas agora com as marcas de papéis e resíduos da aventura humana que tornou aquele dia um momento especial.

Sob o pretexto de adensar a abordagem sobre a série Glass House, duas outras, produzidas mais recentemente, merecem ser brevemente referidas aqui, ainda que com o limitado propósito de endereçar o leitor a elas. A primeira, de 2011 , reúne imagens feitas sobre exteriores e interiores de edifícios projetados pelo arquiteto Gregori Warchavchik, produtor de uma casa que abrigou a primeira exposição do artista. A segunda, de 2012, foi dedicada ao prédio do Museu de Arte Contemporânea da Universidade de São Paulo (MAC-USP), antiga sede do Departamento de Trânsito de São Paulo, DETRAN, um grande edifício de autoria de Oscar Niemeyer, vizinho no tempo e no espaço do conjunto edificado do Parque Ibirapuera, separado irreversivelmente dele a partir da construção da avenida Rubem Berta, nos anos 1960.

Nesses dois conjuntos de fotos, chama a atenção o modo como é desmontada a ideia de pureza, razão e equilíbrio habitualmente associada à arquitetura moderna. Fazendo eco com a maneira com que lida com a cidade, sublinhando as multidões desbaratadas, os transeuntes caminhando como que automaticamente para lá e para cá, como se não
Agnaldo Farias

Reflexos da Casa de Vidro, de Philip Johnson, arquiteto, ou o processo de trabalho de Mauro Restiffe, fotógrafo. 
ARS tivessem um destino certo, como dotados de uma cegueira produzida ano 15 pelo foco excessivo nas obrigações cotidianas, Restiffe, sobretudo no n. 29 caso da reforma do MAC-USP, onde se deu a transformação de um prédio até bem pouco ocupado pela burocracia para sua serventia atual de sede de museu de arte contemporânea, evidencia os pontos obscuros, as gambiarras, o limite tênue que separa a restauração do prédio de sua decadência passada e futura.

Interessa-lhe também, como se verifica nos dois casos, a visão da cidade oferecida pelos prédios, por exemplo, as bordas sinuosas do Cícero Prado, de Warchavchik, acompanhando as curvas do viaduto que desemboca na avenida Rio Branco saltando por cima da via férrea, e, nas miradas no alto do MAC-USP, a arquitetura como trincheira da cordilheira de edifícios.

\section{Os reflexos, as luzes e as sombras}

Como já se indicou, o emprego do vidro na arquitetura já em sua primeira mostra individual com o objetivo de explorar uma fértil dobradiça entre ela e a fotografia, confirmava a compreensão do artista sobre o problema da reflexão, fenômeno que ele havia explorado em pelo menos uma peça, The mirror, de 1999, numa direção que se revelaria ainda mais fértil ao redor de 2007, com a produção da série Reflexão, cujas fotografias nascem da revisitação de outras fotografias suas, instaladas em casa de amigos e colecionadores. Emolduradas e devidamente protegidas com vidros, de acordo com o procedimento padrão, Restiffe cuidava em fotografá-las em ângulo, transformando-as em verdadeiros espelhos que refletiam frações cuidadosamente editadas do ambiente em que estavam, sempre impedindo, em contrapartida, que se soubesse o conteúdo da imagem original. Esse procedimento que transforma sua fotografia num campo reflexivo, ou seja, um campo produtor de uma nova imagem que, ao final, também é sua, junta-se sua peculiar problematização da luz.

Um conjunto de cinco fotografias realizado em 2008, Five on fifth, é disso um magnífico exemplo. Cinco imagens feitas no nível da rua, em meio a multidão de pedestres, todas elas à contraluz do sol de fim de tarde que, juntamente com o perfil do Empire State Building, domina o desfiladeiro formado pelos prédios da $5^{\text {a }}$ avenida, em Nova Iorque. O sol na cara da câmera transforma as pessoas em silhuetas, 
planifica-as, assim como os edifícios, convertidos em paredões entre brilhantes e opacos do grand canyon urbano. As pessoas vêm e vão, não se consegue distinguir ao certo, mas o fato das fotos terem sido feitas em ângulos que variavam do nível abaixo até a altura da cabeça delas, garante um efeito eloquente, como se caminhassem em direção ao sol, ávidas de luz, ou simplesmente tornadas magníficas por estarem sendo banhadas por ela.

\section{Dentro e fora da Glass House - fotografia, pintura, arquitetura e pai- sagem}

De posse de sua desenvoltura no trato com o espaço, com as dobras e sobreposições que vidros, luzes e sombras fabricam, treinado em explorá-lo tanto no âmbito exterior quanto no íntimo, controlando o jogo com objetos e elementos arquitetônicos, e, acima de tudo, atraído pelo vidro como o mais poderoso dos materiais capazes de produzir imagens, Restiffe chegou à pequena Glass House em dois finais de tarde ensolarados, duas sessões de duas horas cada, sempre armado de seu modus operandi, sua Leica M6 e um estoque de 6 a 8 rolos de filmes de alta sensibilidade à luz, cada um com 36 poses. Foi até lá para inspecionar as peculiaridades da construção de pele de vidro e a geometria concisa de seu exoesqueleto metálico. As fotos foram feitas no primeiro dia, donde se conclui que a segunda visita serviu apenas para confirmar se já estava tudo resolvido, se havia capturado tudo o que queria (com a particularidade de que essa segurança foi estabelecida no escuro, uma vez que as fotos não haviam sido ainda reveladas, posto que, diversamente do equipamento digital, cujos resultados são efetivamente instantâneos, o analógico é muito mais lento, pressupondo a passagem pelo tempo lento da revelação pela química do laboratório, a ampliação subsequente mesmo que sob a forma de contato).

Andando de um canto a outro, inventariando os ambientes sutilmente definidos pela disposição dos móveis e objetos que lá são rarefeitos, investigando as particularidades daquela arquitetura que se desfaz através dos raios de luz, o artista, no interior dessa casa com a qual possivelmente sonhara, ele que há tanto tempo estudava o universo dos reflexos, descobriu, do mesmo modo que Mies van der Rohe trabalhando com maquetes de vidro que, nela, acima de tudo, "o importante é o jogo de reflexos”.
Agnaldo Farias

Reflexos da Casa de Vidro, de Philip Johnson, arquiteto, ou o processo de trabalho de Mauro Restiffe, fotógrafo. 
Observando com vagar e prudência, submerso que estava em ano 15 seus próprios reflexos, nesse ambiente capaz de erodir toda e qualquer

ก. 29 materialidade, Restiffe flagrou e tirou partido não só dos reflexos provenientes do efeito da transparência do vidro, que ele explorou, como se verá mais adiante, nos dois modos explicados por Colin Rowe e Robert Slutzky, no seminal texto de 1963, "Transparência literal e fenomenal". Às fotos, soma-se a exploração dos reflexos resultantes da luz e do vidro, sua acuidade em analisar a relação entre linguagens e tempos, mais precisamente, a relação histórica entre pintura, arquitetura e paisagem, relação premeditadamente ativada por Johnson e que até o presente não havia merecido uma tradução à altura.

Afora os reflexos entre o dentro e o fora, as imprevistas fusões entre arquitetura e paisagem, a perda de substância de ambas e sua transformação em imagem, todas as fotografias que compõem a série Glass House têm uma pintura como protagonista, a única pintura da casa, uma obra do pintor francês Nicolas Poussin, mais precisamente uma das três versões existentes de O funeral de Phocion, realizada em 1648. Embora extraordinária, a presença dessa obra, ao menos à primeira vista, é um acontecimento inusitado. O que faria ali, na casa de um membro atuante da primeira e mais importante instituição dedicada à arte moderna, uma obra do século XVII? O próprio Johnson esclarece as razões da presença dessa peça, de resto escolhida e sugerida por Alfred H. Barr Jr., primeiro diretor do MoMA, que, juntamente com a escultura de Elie Nudelman, passou a habitar a casa desde sua inauguração:

Estilisticamente, a Glass House é uma mistura de Mies van der Rohe, Malevich, Parthenon, jardim inglês, o Romantismo como um todo, a assimetria do século XIX (...) é mais um projeto paisagístico que um trabalho de arquitetura. É mais a memória dos jardins ingleses do século XVIII, e que são chamados de jardins ingleses por alguma razão. Não há jardim em lugar algum, quer dizer, não há flores, como os americanos costumam associar quando pensam em jardins. É apenas um tipo de paisagem na qual eu me concentrei na colina onde ela está situada e no carvalho.

A pintura de Poussin aparece no centro de todas as oito fotos que compõem a série, incluindo a oitava, um díptico horizontal, duas vistas à contraluz realizadas fora da casa, quando, à maneira do que acontece 
54

com a magnífica e ambígua tela de René Magritte, O Império da luz, a claridade do céu diurno, que se vê acima e através da casa, contrasta com a penumbra na qual ela está submersa, com os móveis transformando-se em silhuetas, com as árvores, espectrais, sobrepondo-se a ela, roubando-lhe a claridade.

A pintura de Poussin é documentada de frente, de costas, de lado, em ângulo aberto e fechado, quase sempre um fundo que, somado ao vidro, no geral amplifica o efeito especular, a não ser quando se transforma na lateral de uma lâmina escura, opaca em sua parte inferior, suavemente brilhante na metade superior. Em todas as vezes Restiffe ajusta a paisagem descrita pelo pintor com a paisagem que circunda a casa. Reagindo a tendência do mestre francês em fazer uso das árvores para emoldurar uma cena determinada, no caso da tela em questão o funeral de um homem, o estadista ateniense Phocion, alvo de um texto de Plutarco, Restiffe faz com que as árvores do entorno, além de emoldurarem a casa de Johnson, confundam-se com ambas, casa e pintura, num jogo de sobreposições, num amálgama de reflexos.

A sequência das imagens equivale a um pequeno tratado sobre as questões até aqui arroladas e outras que virão a seguir. Na primeira delas, a pintura é fotografada frontalmente, com seu clássico formato retangular guardando a mesma distância do teto e do pilar de metal que está à nossa esquerda, deixando ver a imagem escurecida da paisagem, pressentida pelas copas das árvores altas situadas à direita e à esquerda do primeiro plano da pintura, o céu separado de uma cordilheira vegetal, a mancha branca na extremidade inferior e, no centro, o corpo de Phocion sendo carregado. Mesmo mal iluminada, é possível acompanhar a sugestão do enquadramento feito pelo nosso artista enunciando a irradiação da paisagem clássica mentada pelo pintor francês através da textura da vegetação real, perceptível pela faixa estreita de vidro. E se a pintura está ensombrecida, a vegetação lá fora, por sua vez, está evanescente, como que atacada por excesso de luz filtrada através dela. Ainda do lado esquerdo da imagem, além do pilar referido, é a própria casa que se despacha para fora dos seus limites. Tem-se já aí as duas qualidades de transparência constatadas por Rowe e Slutzky, a transparência literal, decorrente da natureza material do vidro que deixa ver ou traz para dentro o que está do lado de fora, e a transparência fenomenal, levando a casa para onde ela não está, transformando-a em imagem e, nesse sentido, fazendo com que ela assuma a mesma aparência evanes-
Agnaldo Farias

Reflexos da Casa de Vidro, de Philip Johnson, arquiteto, ou o processo de trabalho de Mauro Restiffe, fotógrafo. 
cente, esgarçada dos troncos das árvores que estão à esquerda do pilar. As vistas anguladas da pintura de Poussin dão a ver claramente as sutis calibragens do nosso artista buscando casar a paisagem da pintura com as árvores lá fora ou, melhor dizendo, com as imagens das árvores lá fora, dado que, descontado o fato de que estamos diante de fotografias, o que todas elas trazem são imagens, nem mais nem menos, às vezes nítidas, em soluções que variam de reflexos translúcidos, cristalinos e diáfanos, até reflexos esmaecidos, perdidos em refrações, semelhantes a imagens obscuras como raio $X$, ou estouradas, como as obtidas por meio de superexposições.

Realizada fora da casa, a segunda foto inverte os termos do problema, transformando a pintura num momento positivo, um parêntese de objetividade obtido pelo vão aberto da porta, em contraposição a uma natureza luxuriante colada às paredes de vidro, a dissolução e confusão das fronteiras entre o dentro e o fora, a monstruosa irrupção dos efeitos especulares, para lançar mão de um célebre comentário de Jorge Luis Borges acerca da natureza do espelho "um dispositivo monstruoso pois, como a cópula, reproduz". A imagem tem aqui seu quinhão de natureza enquanto a natureza desfaz-se em imagem, tema que desde a Pop art, com Hamilton, Warhol e Lichtenstein à frente, vem ocupando alguns dos principais artistas e pensadores, sendo o próprio tomado como um legítimo pensador que lança mão de outra linguagem que não a verbal. A fragilidade das imagens corresponde aos frágeis limites das representações, especialmente numa casa tão exposta, sem os atributos das paredes sólidas a confinar corpos e mentes em ilusões de apaziguamento e segurança.

Obtida através de um ângulo entre 20 e 30 graus, a terceira fotografia, ao passo que conserva a pintura como protagonista, nivela mais a paisagem pintada por Poussin com a paisagem exterior, testando entretanto o modo como ambas sofrem efeitos distintos da luz: do lado de fora há uma árvore irreal, esgarçada pela luz que, não bastasse isso, insinua-se pelo interior da casa, erodindo o pilar que também faz as vezes de moldura da foto; do lado de dentro, a luz permite que se perceba melhor a cena, ainda que a extremidade inferior direita, aparentemente mais próxima em razão da pintura deslocar-se diagonalmente para esquerda, tenda a se comportar como uma superfície brilhante, do mesmo modo que a moldura e o chão de tacos de madeira. Note-se a precisão com que a imagem fotográfica faz coincidir as linhas metálicas 
do caixilho com as linhas do cavalete em que a pintura está fixada, engatando um no outro, induzindo a pensá-los como campos conexos. A arquitetura, discretamente separada da paisagem real, transmuta-a em paisagem virtual, fugidia, por meio de sua epiderme vítrea, ligando-se à paisagem virtual estampada na pintura.

A quarta fotografia, tirada novamente no interior da casa, pega o vidro de frente e a pintura num ângulo ainda mais fechado, o que a transforma numa superfície preta brilhante, sobretudo na sua terça parte superior, com o que ela acompanha as bordas superiores das copas das árvores ao fundo, árvores que estão do outro lado do vale em cuja borda a casa está situada. Fotografado frontalmente, o vidro põe em risco a cena toda, provocando a sobreposição de imagens dos elementos interiores com exteriores. $\mathrm{O}$ recurso do contraluz obtém dos elementos verticais dos caixilhos sua regressão à condição de silhuetas, o que os faz se estabelecer em contraponto à verticalidade irregular dos troncos e suas ramagens ainda mais delicadas em razão do esgarçamento que a parede de vidro lhes opera.

A quinta foto da série é a que mais destaca o campo da pintura, ainda que praticamente submerja a imagem numa espessa penumbra. Fotografada em ângulo numa distância mais curta, à queima-roupa, o plano da pintura ultrapassa os limites do campo da pintura, salvo nas diagonais das extremidades inferior e superior esquerdas, o que reforça a sensação de que ela avança obliquamente sobre a fotografia que estamos vendo, ao mesmo tempo que sobre a paisagem lá fora, com o risco de engoli-la por completo. Essa ideia de absorção de um termo pelo outro -pintura/foto/paisagem - está explicitado na sutileza com que a linha superior do conjunto das copas das árvores pintadas conflui para os galhos das árvores plantadas. Porém, se a imagem da pintura está quase totalmente rebaixada pela falta de luz, a paisagem lá fora perdeu sua materialidade justamente pelo efeito contrário: o excesso de luz. É ela, cuja presença é virtude da alta sensibilidade do filme utilizado e do vidro, a corresponsável pela corrosão aparente dos recursos vegetais, como também do caixilho de metal que faz o limite esquerdo da fotografia, com sua integridade comprometida pela floração de pequenas chamas luminosas.

A sexta foto é extraída do lado de fora da casa e, como as outras, mantém a centralidade da pintura, muito embora a retenha pelas costas. E é por esse ponto de vista que ela melhor funciona como espelho,
56

Agnaldo Farias

Reflexos da Casa de Vidro,

de Philip Johnson, arquiteto,

ou o processo de trabalho de

Mauro Restiffe, fotógrafo. 
ARS pois, contraposta ao vidro, sua face escura convida à aderência da imaano 15 gem proveniente do exterior e faz com que ela surja nítida, cristalina, n. 29 ainda que enviesada. A continuidade com o exterior é total, uma vez que a paisagem de Poussin não lhe divide o protagonismo. $\mathrm{O}$ exterior envereda-se casa adentro, colando-se nas costas da pintura e na única parede construída no interior da casa, que também lhe serve de anteparo. O teto, o vidro da parede ao fundo, até mesmo a escultura de Nudelman, tudo se desfaz em reflexos da natureza. Vista desse modo, a casa revela a ideia primordial de Johnson, ideia ignorada mas genialmente intuída por Restiffe, que a verdadeira intenção do arquiteto era projetar a paisagem. A essa intenção faz elevar um segundo propósito que, salvo melhor juízo, nunca foi suficiente ou convincentemente explicitada pelo arquiteto, o projeto de uma casa de imagens.

A sétima e penúltima imagem escurece de vez a pintura, converte-a num plano escuro quadrangular com o mesmo valor da parede opaca que está a seu lado. A natureza se emancipa da pintura, embora não consiga se descolar de sua condição de imagem. A menção à pintura aparece por uma outra via: à flutuação dos dois planos trapezoidais pretos dispostos desalinhados um em seguida ao outro, contrapõe-se o plano trapezoidal do vidro, situado em direção divergente e, pelo alto, o plano branco do forro, arrematado com linhas pretas. Judiciosamente composta, a fotografia presta um tributo às composições abstrato-geométricos, particularmente às pinturas suprematistas de Kazimir Malevich, com seu jogo de planos trapezoidais reversos, desencontrados, flutuando no espaço, as primeiras a estilhaçar concretamente a placidez da superfície pictórica.

A oitava e última foto é um díptico composto por duas imagens retangulares colocadas uma ao lado da outra, o que reitera o formato estabelecido pela pintura no tratamento desse tema voltado para a tensa contraposição da tíbia e trôpega verticalidade humana, com sua melancolia e finitude ("Entretanto você caminha melancólico e vertical", escreveu Drummond) com a linha de horizonte, sempre além e dominante, a exercer sobre nós a força da gravidade. Tomando-as, ambas, à contraluz, subtraindo quase totalmente teto e piso, o artista, carregando as silhuetas, dissolve de uma vez os vidros, planifica os objetos ou os torna corpos enigmáticos, indistintos, um e outro escapando das trevas pelo estilhaçar de luzes. Como uma última fulguração, um balbucio, a casa desaparece e o ambiente doméstico fica como que deixado ao 
relento, aguardando a chegada da noite quando toda a existência se dissipará por algumas horas.

O conjunto das fotografias que compõem essa série de Mauro Restiffe revela ainda dois processos contidos na história das relações entre pintura, arquitetura e paisagem. $\mathrm{O}$ primeiro deles refere-se ao fato de que a paisagem projetada por Johnson em sua Glass House, como ele próprio contava, nasceu da tentativa de levar para o lado de fora, junto do carvalho preexistente, a paisagem pintada por Poussin. Procedendo desse modo, Johnson evocava com consciência a origem histórica do jardim inglês, nascido justamente das leituras que os paisagistas ingleses fizeram das pinturas do barroco francês do século XVII, sobretudo as paisagens pastorais de autoria de Nicolas Poussin e Claude Lorrain. Não será o caso, aqui, de detalhar essa interessante passagem das relações entre linguagens artísticas, mais um tópico a ilustrar o pensamento de Oscar Wilde, segundo o qual, a vida imita a arte muito mais que a arte imita a vida. Mas será conveniente lembrar os versos de Alexander Pope, escritos em 1731, em seu elogio ao conde Richard de Burlington por seu trabalho no desenvolvimento dos jardins de Stowe, em Buckinghamshire, Inglaterra, assentados numa visão de natureza diametralmente oposta aos de extração francesa, que, como se vê em Versailles, eram geometrizados, ordenados, submetidos à razão. Pope ressalta a potência da natureza dos jardins que vinham sendo produzidos desde o começo do século em que vivia, uma compreensão originada na pintura francesa. Escutemo-lo:

\section{To build, to plant, whatever you intend, To rear the Column, or the Arch to bend, To swell the Terras, or to sink the Grot; In all, let Nature never be forgot.}

Mas qual Natureza? leva-nos a pensar essas imagens de Restiffe. Esteja-se dentro ou fora da casa de vidro que Johnson fez nascer num platô elevado, o que se tem é uma corroboração da poética de Mies van der Rohe, que arrancou da ideia de habitação a correlação com as ideias de proteção e confinamento, abrigo e opacidade, espaço íntimo como espaço inescrutável, para, em contrapartida, apresentá-la como matéria evanescente, dissolvida no mundo. Os espaços se interpenetram e, como demonstram essas imagens, ambos perdem a substância que até ali os notabilizava. Não são mais tangíveis, palpáveis e seguros,
58

Agnaldo Farias

Reflexos da Casa de Vidro, de Philip Johnson, arquiteto, ou o processo de trabalho de Mauro Restiffe, fotógrafo. 
A contundente verdade contida nessas imagens de autoria de Mauro Restiffe ganha um sabor adicional, um valioso insumo na compreensão do processo de trabalho artístico, quando se descobre que o artista não tinha conhecimento da genealogia histórica de Poussin e Lorrain/jardim inglês, como tampouco sabia do uso calculado que Johnson fez da pintura para a produção de seu jardim. Com todas suas deficiências e reduções, este texto, lido pelo artista em sua primeira versão, surpreendeu-o por revelar a ele uma parte do que fizera. Pois a ignorância desses fatos não o impediu de decifrar a narrativa, o intrincado palimpsesto proposto pelo arquiteto, mais do que isso, intuir, revelar e explorar os conhecimentos desencadeados, encenados pela Glass House, o que comprova que a inteligência acontece por múltiplas sendas e que bem faríamos se encarássemos as obras de arte como produtos refinados do espírito e não como simples ilustrações de nossas teses.

Referiu-se aqui aos aspectos proporcionados por essa série. Quais seriam eles? Repassando, além das fertilíssimas interseções formais e históricas entre fotografia, pintura, arquitetura e paisagem, a oxigenação dessas linguagens por intermédio de uma fotografia que percebe suas relações e delas constrói outras mais, há ainda o modo renovado como o artista encara e coloca o problema do vidro, as injunções de uma casa ou construção qualquer feita dele ou material sucedâneo, de presença ubíqua na vida contemporânea. Por esse conjunto de imagens percebe-se em nova perspectiva a ontologia desse material, sua falta de vida interior, de movimentos das entranhas que percebemos no ferro, madeira, pedra, tijolos, barro, terra etc., a que chamamos de tempo. O emprego de materiais reluzentes, transparentes e, em consequência, espelhados, reflexivos, é sintomático do opressivo culto atual da permanência, do desejo de presente perpétuo. Vemo-nos nas coisas, trocamos com ela, e a casa é a primeira ou a principal das nossas peles, mais durável do que as roupas, e com a qual desenvolvemos sentimento de familiaridade, assistimos curiosos à aparição de fendas e fungos, aos sons noturnos, ao estalar das madeiras, ao murmúrio reverberante dos encanamentos. O contato continuado com esses fenômenos leva-nos à compreensão de que, como eles, acusamos a passagem do tempo. Por sua vez, uma casa de vidro, como as vitrines das lojas, as fachadas dos prédios, as paradas de ônibus, expõe-nos excessivamente, descobre- 
-nos, como a personagem da novela de Robert Silverberg (O labirinto, 1969) que, tendo sido "aberto" por alienígenas curiosos em entender o que era aquele estranho ser que pela primeira vez encontravam, não foi devidamente "fechado", o que o deixou totalmente exposto, não suas entranhas, mas seus sentimentos; agora integralmente devassável e, portanto, insuportável aos que lhe eram próximos, não lhe restou outra opção a não ser o recolhimento em definitivo, como um eremita, num labirinto. Uma casa na qual sua tangibilidade volatiza-se e, junto com ela, por força de sua materialidade, tudo o que lhe está dentro e fora, parece dispor sobre o desequilíbrio na relação entre tempo e espaço. Sob esse ângulo a constatação de Borges, já mencionada, acerca da monstruosidade do vidro, parece mais verossímil do que à primeira vista se pensa. Viver numa casa assim, e o fato é que mais e mais estamos vivendo em ambientes assim, equivaleria a viver no interior de uma fotografia, com a ressalva de que uma fotografia fica amarelada, o papel vai se enchendo de gretas microscópicas e sua promessa de eternidade vai se desfazendo na proporção do esmaecimento das imagens que ela porta. Já o vidro não, a configuração estável de suas moléculas garante que sobreviva a nós. E sua presença discretíssima, confundida entre água e ar, faz com que não prestemos muita atenção a ele.

A pintura de Poussin no interior da casa de Philip Johnson, foi a fonte geradora de uma paisagem facultada pela construção de uma arquitetura, renovando uma reverberação que vem de longe, um fenômeno de relações entrecruzadas, de resto intensa e constante no âmbito das artes. Mauro Restiffe faz imagens incluindo a fotografia nesse intercâmbio de linguagens e demonstrando que é ele que chamamos de realidade.

\section{Agnaldo Farias}

Reflexos da Casa de Vidro, de Philip Johnson, arquiteto, ou o processo de trabalho de Mauro Restiffe, fotógrafo. 
n. 29 BORGES, Jorge, Luis. Tlön, Uqbar, Orbis Tertius. In: Obras Completas. Buenos Aires: Emecé Editores, 1974.

JOHNSON, Philip. Mies van der Rohe (exhibition catalogue).

NY: MoMANY, 1978, 3a ed.

POPE, Alexander. Epistles to several persons: epistle IV to Richard Boyle, Earl of Burlington. Disponível em: <https://tspace.library.utoronto.ca/html/1807/4350/poem 1632.html>.

QUEST-RITSON, Charles. The English garden: a social history. David R. Godine, 2003.

ROWE, Colin; SLUTZKY, Robert. Transparencia: literal y fenomenal. In: Manierismo y arquitectura moderna y otros ensayos. Barcelona: Gustavo Gili, 1978.

SCHULZE, Franz (ed.). Mies van der Rohe - critical essays.

NY: MoMANY, 1989.

SILVERBERG, Robert. O labirinto. Porto: Europa/America, 1969.

Agnaldo Farias é professor da Faculdade de Arquitetura e Urbanismo da USP, Foi curador geral do Instituto Tomie Ohtake (2000/2012), do Museu de Arte Moderna do Rio de Janeiro (1998/2000) e curador de exposições temporárias do Museu de Arte Contemporânea da Universidade de São Paulo (1990/1992). Foi também curador geral da 29a. Bienal de São Paulo (2010), da representação brasileira da 25a. Bienal de São Paulo (1992), curador adjunto da 23a Bienal de São Paulo (1996), curador internacional da 11ª Bienal de Cuenca, Equador (2011) e do Pavilhão Brasileiro da $54^{a}$ edição da Bienal março de 2017. de Veneza (2011). 